Experts, held in Montevideo in 1948, and now two more volumes have been published: "Ecuador, No. 1" (pp. 74, 1952), and "Argentina, No. 3" (pp. $150,1952)$. In these two volumes, which are published by the Unesco Centre of Scientific Co-operation for Latin America, Montevideo, the usual practice is followed of including first a list of institutions, indicating their scope and resources and giving the names of their chief officials, and then an alphabetical list of scientific workers, in which the publications and field of work of each worker are listed. Further volumes are promised for Argentina.

\section{Study of Psychology in the United States}

A sTUDY of the development and status of research and education in psychology in the United States is being undertaken by the American Psychological Association and will be conducted in two parts : one part will be an evaluation of the status of psychological knowledge; and the other an analysis of occupational, educational and institutional relations of scientific psychology. The study will include a survey of methodology, theory and applications of psychology to determine the interrelationships among various branches of psychology and the importance of psychology to other scientific fields. Problems in psychological education, man-power, research support, communications and administration will also be examined. The project, which will cost about 40,000 dollars, derives its financial support from the National Science Foundation as another in the series of studies of specific fields of science which will assist the Foundation in developing a national science policy in the United States.

Declassified Information on Atomic Energy Piles

A REVISED edition of a report from the Atomic Energy Research Establishment, Harwell, entitled "A Quantitative Study of Uranium-Graphite Lattices" $(R / R 922$; pp. $28+12$ pl. London : H.M.S.O., 1952 ; 6s. net), by Profs. E. A. Guggenheim and M. H. L. Pryce, which was first issued on August 11, 1945, has recently been declassified and published. Calculations and results are given concerning piles of natural uranium rods arranged as a lattice in graphite. The quantity of uranium required for the pile to react steadily, the reproduction constant $k$, the square of the migration length $M^{2}$, and the Laplacian $(k-1) / M^{2}$ are particular quantities specified. The calculations show the effect of varying the radius $a$ of the uranium rods and the radius $b$ of the moderator cell. Both $k$ and the Laplacian each have a maximum, while the critical mass of uranium has a minimum. For a cylindrical pile with height equal to diameter, composed of uranium rods sheathed in $1.15 \mathrm{~mm}$. of aluminium, arranged as a lattice in a graphite moderator and surrounded by a graphite reflector, the minimum quantity of uranium required is given as 26 tons. In this case $a=1.25 \pm 0.10 \mathrm{~cm}$., $b=11.5 \pm 0.50 \mathrm{~cm}$., and the width of the air-gap surrounding each rod $=1.5 \pm 0.25 \mathrm{~cm}$. The effect of varying the air-gap is considerable, and the reasons for this are discussed. In a homogeneous pile the important factor is the proportion of uranium to graphite, and this is shown to remain approximately constant for variation in $a, b$ and the air-gap. The report includes fourteen tables, three diagrams illustrating the neutron cycle, the neutron distribution with an air-gap and with an aluminium layer and air-gap, and eighteen graphs. The above report was edited for the purpose of declassification by C. A.
Rennie. Interested readers may well like to refer also to another A.E.R.E. report $(R / L 5)$ by C. A. Rennie, entitled "Lecture Notes on Pile Theory" $(R / L 5$; pp. $29+3$ pl. London: H.M.S.O., 1952 ; 5s. net), in which the basic nuclear design features of natural-uranium graphite-moderated thermal reactors are dealt with. This report includes references to published papers containing fuller treatment.

\section{Stomatal Behaviour in the Onion}

Since the stomatal guard cells in the onion (Allium cepa) contain neither chloroplasts nor any visible quantity of starch, but do respond to changes in light intensity (which cannot be attributed to concomitant changes in temperature, etc.), the classical explanation of stomatal movement in terms of the starch $\rightleftarrows$ sugar mechanism cannot apply. Whether the hydrolysis of a soluble polysaccharide is involved has not yet been investigated. This interesting case of stomatal behaviour has recently been investigated by O. V. S. Heath (New Phytol., 51, No. 1, 30; 1952), who has advanced various hypotheses to account for effects observed during the course of the relevant experiments.

\section{Conference on Plant and Animal Breeding}

A ONE-DAX conference on "Plant and Animal Breeding" will be held under the auspices of the Joint Biology Committee and the Association of Agriculture at University College, London, on March 7. Mr. Alexander Hay, general secretary of the Association of Agriculture, will take the chair, and the speakers in the morning session will be Prof. L. S. Penrose, Galton professor of eugenics in University College, London, whose subject will be "Present-day Human Genetics", and Dr. Arthur Walton, deputy director of the Agricultural Research Council Unit of Animal Reproduction, Cambridge. The latter, in a talk entitled "Animal Genetics", will deal with the improvement of farm animals through modern breeding methods. In the afternoon Mr. W. B. Barker, of King's School, Wimbledon, will speak on "Teaching Genetics in School", and the conference will close with an address on "Plant Breeding Genetics" by Dr. G. D. H. Bell, director of the Plant Breeding Institute, Cambridge, who will describe the application of Mendelian principles to the work of increasing food production through crop improvement. The fee for the conference is 5s., and application should be made as early as possible to the Secretary, Joint Biology Committee, c/o British Social Biology Council, Tavistock House South, Tavistock Square, London, W.C.1.

\section{Discussion on Collagen}

AN informal discussion on the "Nature and Structure of Collagen", under the auspices of the Colloid and Biophysics Committee of the Faraday Society, will be held in the Wheatstone Physics Laboratory, King's College, London, W.C.2, during March 26-27. It is hoped that the response will be such as to allow for a small number of papers on the biological background to the subject, although the chief emphasis on this occasion will be given to physical and chemical studies of native and extracted or precipitated collagens. 'The biochemical studies of the amino-acid and polysaccharide contents of collagens of various origins now in progress in various laboratories are essential to the understanding of results obtained by means of the techniques of $\mathrm{X}$-ray diffraction, electron microscopy, and infra-red 